\title{
PRÁTICAS RESTAURATIVAS: UMA NOVA ABORDAGEM DAS POLÍTICAS PÚBLICAS DE PREVENÇÃO A VIOLÊNCIA DOMÉSTICA CONTRA MULHERES
}

\author{
RESTORATIVE PRACTICES: \\ A NEW APPROACH TO PUBLIC POLICIES TO PREVENT \\ DOMESTIC VIOLENCE AGAINST WOMEN
}

RODRIGO CRISTIANO DIEHL ${ }^{1}$

ROSANE TERESINHA CARVAlHO PORTO ${ }^{2}$

MARLI MARLENE MORAES DA COSTA ${ }^{3}$

\section{RESUMO}

A violência de gênero tem assumido uma posição crescente e constante nos dados oficiais e, por isso, há a necessidade ainda maior de promover mecanismos de prevenção e de enfretamento. Diante desse cenário, o presente artigo pretende verificar se as práticas restaurativas de fato promovem a efetivação dos direitos de humanos das mulheres que sofrem violência de gênero. Nesse contexto, questiona-se: as práticas restaurativas promovem a efetivação dos direitos de humanos das mulheres que sofrem violência de gênero? Para chegar-se a algumas respostas, buscou-se realizar levantamento de dados sobre os atuais índices de violência de gênero no país; analisar quais são as normativas que disciplinam a aplicação de práticas restaurativas no Brasil e, por fim, trazer alguns exemplos de projetos que já fazem uso de práticas restaurativas em situações envolvendo violência de gênero. Na construção do artigo, usou-se como método de abordagem o dedutivo e como técnicas de pesquisa a bibliográfica e a documental.

Palavras-chave: Gênero. Práticas restaurativas. Políticas públicas. Violência doméstica.

1 Doutorando em Direito pela Universidade de Santa Cruz do Sul com coorientação pelo Programa de Pós-graduação em Ciência Política da Universidade Federal do Rio Grande do Sul, com bolsa Capes. Mestre em Política Social e Serviço Social pela Universidade Federal do Rio Grande do Sul. Mestre em Direito pela Universidade de Santa Cruz do Sul, com bolsa Capes. ORCID iD: http://orcid.org/0000-0002-4869-3112

Lattes: http://lattes.cnpq.br/0284855430208386. E-mail: rodrigocristianodiehl@live.com

2 Doutora e Mestre em Direito pela Universidade de Santa Cruz do Sul. Especialista em Docência no Ensino Superior e em Nova Educação, Metodologias e foco no aluno, ambas pela Pontifícia Universidade Católica do Rio Grande do Sul. Professora na Universidade Regional do Noroeste do Estado do Rio Grande do Sul, lecionando na graduação em Direito e no Programa de Pós-Graduação em Direito - Mestrado e Doutorado. Professora na graduação em Direito e na Pós-Graduação Lato Sensu na UNISC da Universidade de Santa Cruz do Sul). Integrante do Grupo de Pesquisa Biopolítica \& Direitos Humanos (CNPq). ORCID iD: https://orcid.org/0000-0002-1875-5079. Lattes: http://lattes.cnpq.br/4041974927424063. E-mail: rosaneporto@unisc.br

3 Doutora em Direito pela Universidade Federal de Santa Catarina, com pós-doutorado em Direito pela Universidad de Burgos, com bolsa Capes. Professora Permanente do Programa de Pós-Graduação em Direito - Mestrado e Doutorado da Universidade de Santa Cruz do Sul. Coordenadora do Grupo de Pesquisas Direito, Cidadania e Políticas Públicas, cadastrado no CNPq. Professora, psicóloga e advogada. ORCID iD: http://orcid.org/0000-0003-3841-2206. Lattes: http://lattes.cnpq. br/2928694307302502. E-mail: marlim@unisc.br 


\section{ABSTRACT}

Gender-based violence has assumed an increasing and constant position in official data and, therefore, there is an even greater need to promote prevention and coping mechanisms. Given this scenario, the present article intends to verify if the restorative practices in fact promote the realization of the human rights of women who suffer gender violence. In this context, the question is: do restorative practices actually promote the realization of the human rights of women who suffer gender violence? In order to come up with some answers, we sought to conduct a survey of data on the current rates of gender violence in the country; analyze which are the norms that discipline the application of restorative practices in Brazil and, finally, bring some examples of projects that already use restorative practices in situations involving gender violence. In the construction of the article, the deductive approach was used and the bibliographic and documentary research techniques were used.

Keywords: Domestic violence. Gender. Public policy. Restorative practices.

\section{INTRODUÇÃO}

A violência de gênero que vitimiza a mulher é um fenômeno ainda subestimado pela sociedade e autoridades responsáveis pelo encaminhamento, acompanhamento e tratamento dos casos. Nesse cenário, o presente trabalho procura compreender a violência doméstica fundamentada em conceitos desenvolvidos pela psicologia e pelos direitos humanos. As representações sociais da violência doméstica neste trabalho são constituídas por aspectos psicossociais, como por exemplo: o alcoolismo, a drogadição, o baixo nível de escolaridade dos pais, o desemprego, baixos salários, que levam a precárias condições socioeconômicas, etc., tudo isso contribui para o desencadeamento de conflitos psicológicos que levam a depressão, e possibilitam a negligência, o abandono e o desenvolvimento de psicopatologias sérias, como a pedofilia, por exemplo. Apesar de ser um crime e uma grave violação de direitos humanos, a violência contra as mulheres segue vitimando milhares de brasileiras diariamente. Dados publicados no balanço dos atendimentos realizados em 2018 pela Central de Atendimento à Mulher - Ligue 180, revelam que 22,38\% das mulheres em situação de violência sofrem agressões diariamente; em 18,6\% dos casos, a agressão é semanal.

Nesse cenário de legislações internacionais e movimentos contra a violência de gênero, salienta-se que após a criação da Lei Maria da Penha em 2006, o Estado brasileiro ao ratificar documentos internacionais de proteção à mulher, assumiu, no plano internacional, o compromisso de adotar medidas internas para garantir os direitos das mulheres no âmbito das relações domésticas e familiares. Outra inovação em proteção aos direitos femininos, surgiu com a promulgação da Lei $n^{\circ} 13.104$ de 2015, que torna o homicídio de mulheres motivados por razões de condição de sexo feminino uma qualificadora do crime de homicídio, além de passar a caracterizar crime hediondo.

Ainda no âmbito nacional, tem-se a Constituição Federal de 1988 e demais legislações infraconstitucionais, como a Consolidação da Leis Trabalhistas (CLT), o Código Eleitoral, etc. que preveem o direito a igualdade, e inclui tratamento isonômico entre os homens e as mulheres em busca da garantia dos Direitos Humanos das mesmas.

Não obstante, os avanços legislativos não foram o suficiente para conter os casos de violência de gênero no Brasil, uma vez que os índices ainda são assustadores. Assim sendo, 
constata-se que a punição como forma de reeducar o agressor não tem comprovado ser uma medida eficiente. É preciso mais, há necessidade de fazê-lo entender que seu comportamento é errado e não deve ser repetido, pois vai contra a dignidade de outro ser humano. Sabe-se que não é fácil quebrar barreiras culturais, como por exemplo a do machismo, porém é necessário sensibilizar as pessoas, principalmente aquelas de instituições públicas e privadas para que possam intervir na luta contra a violência doméstica, dentro dos limites de suas responsabilidades. 0 desenvolvimento da capacidade do homem de colocar-se no lugar do outro, para exercer a solidariedade, talvez seja o maior e mais urgente desafio a ser enfrentado em nossa época.

Nessa busca por um novo paradigma é que se encontra na Justiça Restaurativa, composta por suas práticas e programas, um meio eficaz de trabalhar-se a violência de gênero, uma vez que proporciona a responsabilização do ofensor e a reparação dos danos sofridos. Contudo, o uso de métodos auto compositivos em casos de violência de gênero ainda é motivo de críticas quanto sua eficácia, pois se teme que resulte na impunidade do agressor.

Diante disso, questiona-se no presente artigo se as práticas restaurativas de fato promovem a efetivação dos direitos de humanos das mulheres que sofrem violência de gênero. Para chegar-se a algumas respostas, buscou-se realizar levantamento de dados sobre os atuais índices de violência de gênero no país; analisar quais são as normativas que disciplinam a aplicação de práticas restaurativas no Brasil e por fim, trazer alguns exemplos de projetos que já fazem uso de práticas restaurativas em situações envolvendo violência de gênero. Na construção do artigo, usou-se como método de abordagem o dedutivo e como técnicas de pesquisa a bibliográfica e a documental.

\section{VIOLÊNCIA CONTRA A MULHER NO BRASIL: LEVANTAMENTO DE DADOS}

A violência de gênero é, há muitos séculos, um problema que inquieta a sociedade. Atingindo principalmente mulheres, as agressões são motivadas pelo sentimento de superioridade e dominação que os homens possuem em relação ao sexo oposto. O gênero "funda-se, pois, numa hierarquia de lugares sociais sexuados que subalternizam o papel feminino" (CAMPOS; CORRÊA, 2012, p. 185). Também nesse sentido, as autoras explicam, que a discriminação começa ainda na infância, onde não raras as vezes, através de práticas nocivas, acontece a negação de direitos fundamentais essenciais ao bem-estar e desenvolvimento sadio do infante, como por exemplo, a preferência por crianças do sexo masculino, violência doméstica, mutilação genital feminina, exploração sexual, discriminação, imposição de afazeres domésticos, casamento precoce, entre tantas outras formas de discriminação existentes.

$\mathrm{Na}$ imposição dos papeis sociais para homens e para mulheres, elas sofreram as maiores desvantagens sociais, desde o início do sistema capitalista, a exploração da mais-valia foi mais intensa para as mulheres, por meio da intensificação do trabalho, extensão da jornada de trabalho e dos salários mais baixos se comparado aos dos homens. Na reconstrução histórica da humanidade, pode-se perceber que tais fatores foram acentuados durante 
a Revolução Industrial, período em que se ampliou a competitividade entre as indústrias e a necessidade de maiores lucros, com isso, as mulheres passaram a ser desejadas pelo mercado por serem cuidadosas, mas também, por se submeterem as regras e aos valores repassados a título de salário, pois deveriam levar o sustento para suas famílias (SAFFIOTI, 2013).

Com base nessa ideia de que o "sexo" seria uma construção social, mas inacabada, as feministas optaram por substituir esse termo pelo "gênero", que descende do inglês gender. A utilização desse novo termo de acordo com Sabadell (2008) possibilita que sejam analisadas as identidades - feminino e masculino, sem reduzi-las unicamente ao plano biológico, podendo identificar essas identidades de acordo com o período histórico. Nos anos 1990 as pesquisas da historiadora americana Joan Scott contribuíram com os estudos brasileiros sobre gênero, utilizando-se das critica acerca do saber produzido pelas diferenças existentes e dos mais variados sentidos atribuídos nos espaços de socialização, tendo como destaque as instituições educacionais (FINCO; VIANNA, 2008).

Para melhor compreensão dos conceitos de gênero, Joan Scott propõe o gênero como categoria de análise histórica, apresentando-o como elemento constitutivo das relações sociais, baseado nas diferenças "percebidas" entre os sexos, como forma primeira de significar as relações de poder. Para ela, o gênero é composto de quatro elementos que funcionam de maneira articulada, mas não obrigatoriamente ao mesmo tempo (CAMPOS; CORREA, 2012).

Nos casos de violência de gênero em que a mulher é a vítima, há um nível de subjetividade e submissão na relação, através da sutileza de coisificação do outro, como algo naturalizado, evidencia ainda mais, que o termo gênero é muito mais que uma construção social e cultural, tal como o sexo é biológico (BEAUVOUIR, 2019). Com base na obra de Simone Beauvoir (2019), publicada primeira vez em 1949 e lançado na França, O Segundo Sexo fica evidenciado que o movimento feminista abriu espaços de interlocuções sobre as desigualdades sociais proveniente da diferença entre os sexos, diga-se de passagem, as relações de poder e de dominação. A obra que trata sobre Fatos e Mitos, critica o determinismo biológico, as abordagens psicológicas e o materialismo histórico e menciona o argumento de que a mulher é uma construção social historicamente determinada. Já a obra intitulada " $\mathrm{A}$ experiência vivida" examina o processo pelo qual a mulher torna-se mulher e como se dá a sua submissão.

Beauvoir refletiu sobre as práticas e mitos históricos que fundamentaram a sociedade e levou a mulher a ser considerada, subjugada como sendo um segundo sexo, inferior e diferente. Além disso, destacou assimetria das relações de poder entre os sexos, em que prevalecia o referencial masculino neutro, e o feminino era considerado o Outro, sempre inferior em relação ao primeiro. Em outras palavras: "A mulher determina-se e diferencia-se em relação ao homem, e não este em relação a ela; a fêmea é o inessencial perante o essencial. O homem é o Sujeito, o Absoluto, ela é o Outro" (BEAUVOUIR, 1970, p. 52). Conforme destacou-se anteriormente a obra de Beauvoir é um marco teórico com outra percepção sobre a mulher em relação ao homem, muito embora tenha se evidenciado que o trabalho mais importante para o feminismo foi de Butler (Gender Trouble) (DIAS; COSTA, 2013).

No Brasil, os números que demonstram a quantidade de casos de violência contra a mulher são alarmantes, principalmente se observados em seu contexto, uma vez que a maio- 
ria das agressões acontece no ambiente familiar e são perpetrados por pessoas muito próximas da vítima.

De acordo com os dados do Ligue 180-Central de Atendimento à Mulher, serviço de utilidade pública oferecido pelo Ministério da Mulher, da Família e dos Direitos Humanos (MMFDH), 98.254 denúncias referentes a violência doméstica e familiar foram registradas no período de janeiro de 2018 a junho de 2019 pelo Sistema Integrado de Atendimento à Mulher (SIAM) e Sistema de Ouvidoria Nacional de Direitos Humanos (SONDHA). É possível observar ainda que as denúncias aumentaram significativamente em 2019, com um acréscimo de mais de 7.000 registros em relação ao período de janeiro a junho de 2018 (MMFDH, 2019a). Referente ao ano de 2018, o balanço anual do Ligue 180 verificou que em $86 \%$ dos registros as agressões foram cometidas por pessoas do sexo masculino. Em $28,44 \%$ das denúncias os suspeitos são os próprios companheiros, em 12,59\% dos casos são ex-companheiros e cônjuges representam $7,65 \%$ dos denunciados. Em relação a frequência em que a violência ocorre, os dados mostram que em $22,38 \%$ dos casos a violência é diária e em $18,26 \%$ é perpetrada algumas vezes na semana. Em 41,29\% das denúncias não foi relatada a frequência com que a violência aconteceu (MMFDH, 2019b). Entende-se, portando, que muitos casos de violência diária podem estar subnotificados nesse último índice.

Ademais, a violência praticada contra a mulher pode tomar dimensões irreversíveis, chegando à morte das vítimas. Essa foi a realidade de muitas mulheres nos últimos anos no Brasil, como será exemplificado através de dados do Atlas da Violência 2019 ao longo deste artigo. Tais homicídios de mulheres, motivados pela condição de sexo feminino, ou seja, pelo simples fato de ser mulher, envolvendo violência doméstica e familiar, por menosprezo ou discriminação, é denominado pela legislação brasileira como feminicídio.

O feminicídio passou a integrar a legislação pátria em 2015, como qualificadora do crime de homicídio através da Lei $n^{\circ} 13.104$, acrescentando ao Código Penal, em seu art. 121, o inciso $\mathrm{VI}, \S 2^{\circ}$-A e $\S 7^{\circ}$. Tal legislação também fez alterações em dispositivos da Lei $n^{\circ}$ 8.072/90, passando assim o feminicídio a caracterizar crime hediondo (BRASIL, 2015). Contudo, apesar de se destacar como um grande avanço para prevenir a violência contra o sexo feminino, a lei por si só não foi capaz de fazer diminuir os índices de homicídio de mulheres motivados por discriminação e menosprezo.

Dados do Atlas da Violência 2019, um estudo realizado pelo IPEA (Instituto de Pesquisa Econômica Aplicada) e pelo Fórum Brasileiro de Segurança Pública, demonstram que o número de feminicídios vem aumentando na última década. Para chegar a dados mais próximos da realidade e ser possível constatar que se trata de feminicídio e não apenas homicídio de mulheres, uma vez que a legislação é relativamente recente e pode haver subnotificação nos registros policiais, o estudo levou em conta o contexto em que a morte se deu, qual seja, ter sido praticada dentro da residência, uma vez que a violência doméstica e familiar são algumas das características do feminicídio.

[...] há reconhecimento na literatura internacional de que a significativa maioria das mortes violentas intencionais que ocorrem dentro das residências são perpetradas por conhecidos ou íntimos das vítimas. Portanto, a taxa de incidentes letais intencionais contra mulheres que ocorrem dentro das residências é uma boa proxy para medir o feminicídio. Naturalmente, ainda que o número real de feminicídios não seja igual ao número de mulheres mortas dentro das residências (mesmo porque vários casos de feminicídio ocor- 
rem fora da residência), tal proxy pode servir para evidenciar a evolução nas taxas de feminicídio no país (CERQUEIRA et al., 2019, p. 40).

Assim, verifica-se pelos dados já referidos que houve um aumento de $38,1 \%$ nos casos de feminicídio entre 2007 e 2017, passando de 1.019 registros em 2007 para 1.407 no ano de 2017. O aumento de homicídios de mulheres praticados com arma de fogo dentro das residências teve da mesma forma um aumento significativo, com um acréscimo de 40,5\% na década já mencionada (CERQUEIRA et al., 2019).

Através dos índices fica, portanto, evidente o que já foi pontuado em parágrafos anteriores: a Lei do Feminicídio, assim como a Lei Maria da Penha, não foram o suficiente para conter os casos de agressão às mulheres motivados por ódio e discriminação. Qual seria então o caminho a ser percorrido para que a realidade de tantas mulheres vítimas de violência seja alterada? A simples punição do ofensor não tem mostrado resultados satisfatórios, é necessário a busca de novos paradigmas que o façam repensar seu modo de agir, evitando que agressões se repitam.

É nesse cenário que as práticas restaurativas, enquanto políticas públicas de pacificação e prevenção de conflitos, passam a ser estudadas e aplicadas nas instituições e nas comunidades, como meio eficaz de trabalhar comportamentos agressivos através do diálogo e da responsabilização, como explica Zehr (2008, p. 170) "[...] o crime é uma violação de pessoas e relacionamentos. Ele cria a obrigação de corrigir os erros. A justiça envolve a vítima, o ofensor e a comunidade na busca de soluções que promovam reparação, reconciliação e segurança". Sobre a Justiça Restaurativa, composta por suas práticas restaurativas, abordar-se-á com mais detalhes no próximo ponto.

\section{PRÁTICAS RESTAURATIVAS E SUA REGULAMENTAÇÃO NO BRASIL}

Há muitas décadas o Poder Judiciário brasileiro, da forma como está estruturado, não tem se mostrado eficaz ao atender o excesso de demandas que lhe são atribuídas. A carga excessiva de processos, burocracia exacerbada e número de servidores insuficiente, têm feito com que a morosidade torne ainda mais difícil a espera por uma resposta do Estado. Diante desse panorama e da falta de identificação com o processo, uma vez que as partes interessadas são tratadas como coadjuvantes durante a tramitação da ação judicial, é que surge o interesse na utilização das práticas restaurativas como meio de resolver os conflitos de forma mais humana e com maior participação dos reais interessados pela solução do litígio. A respeito da forma como o judiciário atua, Costa e Diehl (2017, p. 31) contribuem explicando que

[...] na prestação jurisdicional, os fatores que desencadearam o conflito são considerados insignificantes quando comparados ao ato que ora está sendo objeto de diálogo. Nesse sentido, a resposta do processo judicial é direcionada, exclusivamente, às consequências geradas, e não às suas origens, tratando-se, portanto, de terminar formalmente com o conflito, e não de superá-lo [...]. 
As práticas restaurativas têm origem nas sociedades comunais (pré-estatais europeias e as coletividades nativas) e podem ser observadas entre os povos colonizados da Nova Zelândia, África, Áustria, América do Norte e do Sul (JACCOUD, 2005). Na concepção desses grupos humanos, os conflitos eram tidos como situações a serem resolvidas no seio da própria comunidade onde se desenvolveram. 0 movimento denominado Justiça Restaurativa surge a partir dos anos 70 influenciado pelas propostas de críticos do sistema penal e, desde então, vem sendo gradativamente estudada e aplicada em várias partes do mundo. Contudo, "é a partir da década de 90 que se torna um dos principais movimentos de reforma do sistema criminal, inclusive passando a ser recomendado pela União Europeia e pela Organização das Nações Unidas" (PRUDENTE, 2011, p. 42).

A Justiça Restaurativa se destaca como uma forma de solução de conflitos e reconstrução de relações prejudicadas, baseada na escuta ativa das partes, sensibilidade para com as dores vivenciadas, informalidade, imparcialidade e atenção às necessidades, tanto da vítima como do ofensor, resultando, se chegarem num consenso, na reparação dos danos, mesmo que de maneira simbólica. 0 objetivo das práticas restaurativas, ao contrário do que muito se dissemina, não é essencialmente o perdão, ou ainda, a falta de responsabilização do ofensor, acarretando em sua impunidade. 0 pedido de desculpas e sua aceitação por meio dos demais envolvidos pode ser uma das consequências do procedimento restaurativo, mas não deve ser considerado como a única finalidade do mesmo.

Ademais, os efeitos de um modelo de justiça que abranja tais características podem ser muito significativos, resultando, por exemplo, em uma possível redução do uso da justiça criminal tradicional e consequentemente, "[...] no deslocamento da complexa estrutura vertical de aplicação do poder de punir do Estado (centrado na averiguação da culpa e na imposição de uma sanção penal por terceiros imparciais) para mecanismos de resolução de conflitos que devolvam o conflito às partes e permitam que estas decidam, de forma horizontal, como lidar com a situação tida como problemática" (ACHUTTI; PALLAMOLLA, 2013, p. 203).

Com intuito de promover a base para a implementação da Justiça Restaurativa no âmbito criminal, foi elaborada pelo Conselho Econômico e Social da Organização das Nações Unidas (ONU) a Resolução 2002/12. Tal normativa estabelece princípios para a criação de programas de Justiça Restaurativa em matéria criminal, conceituando o processo restaurativo, sua utilização prática, como os Estados-membro devem realizar a operação de tais programas e quais os cuidados que devem despender para o desenvolvimento contínuo dos mesmos (ONU, 2002).

No Brasil, no ano de 2006, foi elaborado pela Câmara dos Deputados, o Projeto de Lei 7.006 que tem como objetivo "[...] facultar o uso de procedimentos de Justiça Restaurativa no sistema de justiça criminal, em casos de crimes e também contravenções penais" (BRASIL, 2006). Em 2016, tal Projeto de Lei foi apensado ao Projeto de Lei 8.045/2010 do Código de Processo Penal que ainda segue em tramitação.

Em 2010, o Brasil publicou a Resolução 125, trazendo então a necessidade de oferecimento de outros mecanismos de solução de conflitos, em especial os meios consensuais, exemplificando como alternativas a mediação e a conciliação, não vedando o uso de outros métodos autocompositivos, subentendendo-se que a Justiça Restaurativa era passível de ser utilizada. Não obstante, apenas seis anos mais tarde, no ano de 2016, foi criada uma normativa para tratar especialmente da aplicação da Justiça Restaurativa no Poder Judiciário 
brasileiro. A Resolução 225 dispondo sobre a Política Nacional de Justiça Restaurativa no âmbito do Poder Judiciário, considerando, para isso, a resolução 2002/12 da ONU, traz os princípios a serem seguidos para a prática da Justiça Restaurativa em âmbito nacional:

Art. $2^{\circ}$ São princípios que orientam a Justiça Restaurativa: a corresponsabilidade, a reparação dos danos, o atendimento às necessidades de todos os envolvidos, a informalidade, a voluntariedade, a imparcialidade, a participação, o empoderamento, a consensualidade, a confidencialidade, a celeridade e a urbanidade (BRASIL, 2016).

Tais normativas demonstram a preocupação do Brasil em incorporar ao seu ordenamento jurídico uma forma alternativa de solução de conflitos que atenda de maneira mais consistente as necessidades da vítima e promovam a responsabilização do ofensor, fazendo- o repensar sua atitude até mesmo mudar seu comportamento. Através dessa nova concepção de justiça, as partes envolvidas passam a ocupar papéis diferentes dentro da situação conflituosa, ou seja, passam a ser consideradas como peças fundamentais para o andamento do procedimento em busca de uma solução, sendo as suas contribuições e opiniões o que realmente é levado em conta, pois na Justiça Restaurativa a decisão final parte sempre dos envolvidos na situação e não de uma terceira pessoa como ocorre na justiça tradicional a que estamos habituados.

Portanto, nas práticas restaurativas há a presença do facilitador como figura importante na condução dos diálogos. Ele deve atuar de forma imparcial e informal, não criando um ambiente hierarquizado em que as partes possam se sentir constrangidas como acontece, na maioria das vezes, no sistema judiciário. "Atuando como facilitador, o mediador não proporá qualquer acordo, tampouco buscará forçar um entendimento entre as partes, mas exercerá a sua função buscando viabilizar o diálogo entre os envolvidos" (ACHUTTI, 2014, p. 78).

Atualmente, ainda há divergências sobre qual deveria ser o âmbito de aplicação das práticas restaurativas, ou seja, se deveria também ser aplicada em casos mais graves, como a violência doméstica, por exemplo, devido a todas as implicações que esse tipo de crime acarreta. Nesse sentido, será abordado no próximo item, como vem sendo a aplicação das práticas restaurativas em casos de violência doméstica no Brasil, mais especificamente em dois estados brasileiros, quais sejam, Paraná e Rio Grande do Sul.

\section{EXEMPLOS DE APLICAÇÃO DE PRÁTICAS RESTAURATIVAS NOS CASOS DE VIOLÊNCIA DE GÊNERO EM ESTADOS DO SUL DO PAÍS}

Hodiernamente, ainda há muita resistência ao se falar em uso de práticas restaurativas em casos de violência de gênero. Ainda é comum na sociedade a ideia de que outra metodologia que não use da punição para com o agressor irá resultar na banalização de sua atitude e na perpetuação da violência. Nesse sentido, Gomes e Graf (2016) explicam que se pensar no uso de formas autocompositivas em casos de violência doméstica pode causar incômodo por se imaginar que o objetivo é tão somente a reconciliação do casal e como consequência, 
a impunidade do agressor. Contudo, exemplos de aplicação de práticas restaurativas em alguns estados brasileiros têm demonstrado exatamente o contrário.

Na cidade de Ponta Grossa, estado do Paraná, programas de aplicação de práticas restaurativas em situações de violência doméstica já funcionam desde 2015. A atuação do Cejusc/PG referente ao uso de métodos autocompositivos se divide em três fases, sendo a primeira delas o projeto Circulando Relacionamentos. 0 projeto tem o propósito de ofertar práticas restaurativas aos envolvidos em litígios que almejarem participar dessa nova metodologia de resolução de conflito e proporcionar o empoderamento da mulher e a responsabilização do ofensor pelos danos que causou (CEJUSC PONTA GROSSA, 2017). Assim explica o informativo do projeto:

[...] os atendidos pela Delegacia da Mulher e Vara de Violência Doméstica são convidados à participarem do Projeto. Após serem informados acerca das diretrizes e objetivos, caso aceirem participar, devem assinar o Termo de Compromisso Livre e Esclarecido. Aos envolvidos no conflito é oportunizado que possam restaurar as relações, se assim desejarem, ou, não sendo o caso, chegarem a um consenso quanto à reparação dos danos resultantes do conflito, bem como, estabelecer um termo de compromisso para formação do convívio pacífico, abarcando todo e qualquer tipo de divergência ainda existente, seja familiar, cível ou criminal - na medida do possível e respeitando a norma legal vigente e a disponibilidade ou indisponibilidade da ação (CEJUSC PONTA GROSSA, 2017, p. 2).

O informativo do projeto também salienta que o uso das práticas restaurativas não implica na substituição da pena ou aplicação de medidas despenalizadoras, vedada pela Lei n. 11.340/2006, mas ao contrário, serve como complemento à efetiva aplicação da própria lei e como consequência, se espera que seja possível conter os casos de reincidência. Os gráficos usados para ilustrar as informações demonstram o índice de consenso de $100 \%$ referente aos atendimentos de violência doméstica (CEJUSC PONTA GROSSA, 2017). Consoante a ideia de que a aplicação de práticas restaurativas em casos de violência doméstica não resulta em medidas que gerem a impunidade do réu, mas sim, serve de complementação a Lei, importante salientar que a própria legislação traz como previsão em seu art. 45, o comparecimento do agressor a programas de recuperação e reeducação.

A segunda fase do procedimento de atuação do Cejusc/PG é denominada Central de Custódia Restaurativa. Nessa metodologia, as situações são encaminhadas para oficinas de reflexão. Assim sendo, no decorrer da audiência de custódia, "quando juiz e promotor entenderem que é caso de soltura, substituirão a prisão por medida cautelar diversa consistente na participação em oficinas temáticas, utilizando os fundamentos das práticas restaurativas". Ao final das oficinas, é sugerido a realização do Círculo Restaurativo Conflitivo entre o casal e os demais integrantes da família para que se trabalhe o conflito existente, caso tenham interesse.

A respeito da aplicação dos círculos é importante destacar que se trata de uma metodologia muito importante dentro das práticas restaurativas e tem resultados muito positivos, pois como salienta Pranis (2010), proporciona um meio de reunir as pessoas para diálogos difíceis e para trabalhar e superar conflitos. Assim, o círculo é uma maneira de formar a noção mais abrangente possível de nós mesmos, do outro e das questões discutidas, fazendo com que seja possível trilhar de forma conjunta o caminho mais benéfico. 
A terceira fase do processo de aplicação das práticas restaurativas em Ponta Grossa chama-se Projeto Sermais. Nesse procedimento "a seleção dos casos ocorre na dosimetria da pena, quando o juiz substitui a pena em regime aberto pelo comparecimento obrigatório em reuniões que irão discutir masculinidade e gênero" (Cejusc Ponta Grossa, 2017, p.8). Segundo o informativo elaborado pelo Cejusc/PG, são realizados 16 encontros, onde os homens são atendidos por um psicólogo, além de contarem com a presença voluntária de médico urologista, advogado e assistente social.

[...] uma vez concluídas as sessões, tem o réu sua pena extinta, esse projeto tem índice de reincidência inferior a $5 \%$ e, já foi até objeto de estudos do Curso de Serviço Social da UEPG, num trabalho de conclusão de curso que revelou que o programa havia mudado para melhor a vida de 07 de 08 famílias entrevistadas (CEJUSC PONTA GROSSA, 2017, p. 8).

Ainda há, na atuação referente a aplicação de práticas restaurativas pelo Cejusc/PG, a atenção às crianças e adolescentes pertencentes as famílias em conflito. Sendo assim, os filhos dos casais atendidos também passam por acompanhamento psicológico, quando necessário, ou ainda, acompanhamento escolar, se for observada essa necessidade.

Também na região Sul do país, o Estado do Rio Grande do Sul tem atuação importante na aplicação da Justiça Restaurativa em casos de violência doméstica, sendo um dos pioneiros na implantação dessa metodologia. Em entrevista publicada em 2017, a magistrada responsável pelo $1^{\circ}$ Juizado da Violência Doméstica e Familiar Contra a Mulher de Porto Alegre, Dra. Madgéli Frantz Machado, explica que o uso da justiça restaurativa em situações envolvendo violência doméstica passa por várias fases. Em um primeiro momento, pessoas capacitadas para trabalhar com casos de violência doméstica analisam se a situação pode ser trabalhada pelos círculos de restauração. Sendo assim, explica a juíza, que a avaliação sobre quem pode participar do procedimento é bastante rígida, o que comprova exemplificando que dos sete mil casos do Juizado pelo qual é responsável, apenas quarenta e cinco foram encaminhados para o projeto até dezembro de 2016. Destes quarenta e cinco, nenhuma reincidência foi registrada (CANOFRE, 2017).

Trazidos os exemplos de aplicação de práticas restaurativas em casos de violência doméstica, destaca-se por fim, que a Resolução 225 do CNJ, a qual dispõe sobre aplicação da Justiça Restaurativa no âmbito do Poder Judiciário, também prevê o emprego de procedimentos restaurativos em situação de violência doméstica e familiar:

Art. 24 Fica acrescido o seguinte parágrafo ao art. $3^{\circ}$ da Resolução CNJ 128/2011:

$\S 3^{\circ}$. Na condução de suas atividades, a Coordenadoria Estadual da Mulher em Situação de Violência Doméstica e Familiar deverá adotar, quando cabível, processos restaurativos com o intuito de promover a responsabilização dos ofensores, proteção às vítimas, bem como restauração e estabilização das relações familiares (BRASIL, 2016).

Diante do exposto, não pretendendo esgotar os exemplos positivos de implantação de práticas restaurativas em casos de violência de gênero, pois através desta pesquisa foi possível constatar que a aplicação da justiça restaurativa e suas práticas nos casos de violência contra a mulher no Brasil, estão sendo implementadas com excelentes resultados para o casal e seus filhos (quando existentes). Os números revelam o sucesso desta prática que está se espalhando por todo o Brasil, apesar de ainda possuir uma maior concentração na 
Região Sul do país. Encerra-se o presente artigo com a perspectiva de que os rumos em busca de conter a violência doméstica estão tomando novos caminhos que demonstram melhores resultados e acarretam na efetivação dos direitos das mulheres, uma vez que se tornam mais seguras e conscientes de que terão apoio para superar o momento difícil pelo qual passaram. Não é mais aceitável que os conflitos de gênero que vitimizam centenas de mulheres ano após ano no país, continuem dependendo da burocratizada e lenta estrutura do poder Judiciário, o qual foi construído sob o rito de códigos estanques, inconciliáveis com a multiplicidade de procedimentos decisórios exigidos pela sociedade atual (MORAIS; SPENGLER, 2008).

O Poder Judiciário permaneceu imóvel diante das transformações sociais que ocorreram. A jurisdição tradicional encontra-se extremamente assoberbada e ineficiente, pois não foram criadas as transformações qualitativas necessárias para adaptar a jurisdição tradicional às novas formas de conflito que deve enfrentar, restringindo-se a sua estrutura e qualificação aos litígios que podem ser denominados de clássicos (BEDIN; BEDIN; FISCHER, 2013).

A partir da Resolução n. 2002 de 2012 do Conselho Econômico e Social da Organização das Nações Unidas, a metodologia da Justiça Restaurativa e das Práticas Restaurativas se consolidou no Brasil como um novo paradigma de acesso à justiça em seu sentido amplo. 0 Conselho Nacional de Justiça - CNJ, através da Resolução de n. 125/2010 e da Resolução de n. 225/2016, estabeleceu a importância da transposição do contexto social de influência liberal, para uma nova cultura edificada nos pressupostos do humanismo, da solidariedade e do respeito ao outro. 0 pluralismo e a heterogeneidade das demandas que chegam até - Judiciário, postulando inclusive a regulação de questões de caráter particular, instauraram uma realidade de judicialização das relações sociais, demonstrando a necessidade de formação de indivíduos autônomos e corresponsáveis com a resolução de seus próprios conflitos. Assim, diante de uma cidadania ativa, é viável a implementação das Práticas Restaurativas, como modelo adequado à jurisdição tradicional nos casos de conflitos.

A proposta de efetivação da Justiça Restaurativa e das Práticas Restaurativas nos casos de violência de gênero, busca a instituição de uma cultura efetiva de prevenção e de pacificação dos conflitos de gênero que vitimizam as mulheres, que tenha por objetivo encontrar respostas qualitativamente mais adequadas, objetivando prevenir os danos por meio do um paradigma integrador, que tenha como princípios a informalidade, a responsabilidade, a imparcialidade, a participação, a humildade, o mútuo respeito, a boa-fé, a honestidade, o empoderamento e a esperança.

\section{CONCLUSÃO}

Diante dos altos índices e dos poucos resultados satisfatórios advindos das leis que visam conter os casos de violência de gênero, apresentou-se no presente artigo as práticas restaurativas como método alternativo de solução de conflitos envolvendo agressões motivadas por discriminação e menosprezo ao sexo feminino. Sendo assim, questionou-se se as práticas restaurativas de fato promovem a efetivação dos direitos humanos das mulheres que sofrem violência de gênero. 
No decorrer da pesquisa e da estruturação dos tópicos, foi possível constatar que mesmo havendo críticas e dúvidas a respeito da eficácia da aplicação das práticas restaurativas em casos envolvendo violência de gênero, essa metodologia apresenta resultados satisfatórios e, ao contrário do que se dissemina, não resulta na impunidade do agressor. Os exemplos de Estados na Região Sul do país que utilizam o método autocompositivo em casos de violência doméstica e familiar demonstram o quanto satisfatório e eficaz pode ser a realização dos procedimentos restaurativos para promover a conscientização e mudança de comportamento do ofensor, resultando ainda, na grande maioria das vezes, na reparação dos danos, mesmo que de maneira simbólica.

A possibilidade de dialogar e entender o que levou a agressão é muito importante para a vítima, pois significa colocar um ponto final em um capítulo trágico de sua vida e reconstruir sua própria história. No processo restaurativo, terá a oportunidade de expressar o que lhe incomoda e ter suas angústias ouvidas e levadas em conta, diferentemente do que aconteceria na justiça tradicional, em que seu caso seria igualado a tantos outros, sem ter suas particularidades consideradas. A simples punição do agressor, não o fará repensar seu comportamento, tampouco pesar o mal que causou a outro ser humano. Ao contrário, o castigo dado pela pena imposta apenas nutrirá sentimento de vingança.

De uma maneira bastante geral, pode-se dizer que a Justiça Restaurativa é vista como uma forma de resolução de conflitos distinta da imposta pelo modelo de justiça tradicional. Possui princípios diferentes dos sustentados pelo modelo retributivo (da imposição de penalidades) e propõe, dentre outras coisas, a participação da vítima e do ofensor na resolução do conflito, a reparação do dano decorrente do delito (simbólica e/ou materialmente) e a responsabilização do ofensor de maneira não estigmatizante e excludente.

Sendo assim, conclui-se na presente pesquisa, que as práticas restaurativas são uma forma de efetivação dos Direitos de Humanos das mulheres que sofrem violência de gênero, pois contribuem para que tenham maior participação em seu próprio processo e sejam beneficiadas com a reparação dos danos sofridos. Está comprovado que a violência doméstica não começa ou termina simplesmente com a lesão e/ou ameaça. Envolve, em muitos casos, acirradas disputas sobre à guarda, alimentos, divisão de bens, etc. Dessa forma, não é justo que mulheres que já tiveram suas vidas dilaceradas por atitudes tão cruéis praticadas por pessoas tão próximas e de que esperavam receber amor, ainda precisem sofrer revitimizações ao enfrentar um processo judicial estruturado de forma que the conceda um papel de coadjuvante diante de seus próprios direitos.

A Justiça Restaurativa é um novo paradigma de justiça social, capaz de trabalhar a cultura da paz, através de uma política humanizadora e não necessariamente de perdão, mas do exercício do diálogo, do respeito, da solidariedade e da compaixão. O elevado conteúdo pedagógico dos procedimentos restaurativos possibilita que uma solução para o conflito de gênero, surja como consequência natural do processo de comunicação entre o autor e a vítima.

Contudo, apesar do importante passo dado em relação a garantia de direitos de mulheres vítimas de violência doméstica, observa-se que ainda há um longo caminho a ser percorrido para que o número de agressões de fato diminua, mas, para que esse fato ocorra, é necessário o afastamento da naturalização da violência, sobretudo, em uma cultura marcada pelo machismo e pelo patriarcalismo enquanto elementos estruturais. 


\section{REFERENCIAS}

ACHUTTI, D.; PALLAMOLLA, R. Justiça restaurativa e a cultura jurídica brasileira: análise crítica do projeto de lei 7.006/06. In: COSTA, M. M. M.; SPENGLER, F. M (Orgs.). Mediação de Conflitos e Justiça Restaurativa. Curitiba: Multidea, 195-228, 2013.

ACHUTTI, Daniel. Justiça restaurativa e abolicionismo penal: contribuições para um novo modelo de administração de conflitos no Brasil. São Paulo: Saraiva, 2014.

BEAUVOIR, Simone. O Segundo sexo. 6. ed. Rio de Janeiro: Nova Fronteira, 2019.

BEDIN, G. A.; BEDIN, G. L.; FISCHER, R. S. Justiça e direitos humanos: a crise da jurisdição estatal e as novas formas de tratamento dos conflitos. In: DEL'OLMO, F. de S.; GIMENEZ, C. P. C.; CERVI, T. M. D. (Orgs.). Direitos fundamentais e cidadania: a busca pela efetividade. Campinas: Millennium, 2013.

BONAFE-SCHMITT, Jean-Pierre. Os modelos de mediação: modelos latinos e anglo-saxões de mediação. Revista Meritum, Belo Horizonte, v. 7, n. 2, p. 181-227, jul./dez. 2012.

BRASIL. Câmara dos Deputados. Projeto de Lei Complementar 7006/2006. Disponível em:https://www.camara. leg.br/proposicoesWeb/fichadetramitacao?idProposicao=323785. Acesso em: 20 dez. 2019.

BRASIL. Conselho Nacional de Justiça (CNJ). Resolução nº 125, de 29 de novembro de 2010. Disponível em: http://www.cnj.jus.br/buscaatosadm?documento=2579. Acesso em: 20 dez. 2019.

BRASIL. Conselho Nacional de Justiça (CNJ). Resolução n 225, de 31 de maio de 2016. Disponível em: http:// www.cnj.jus.br/atosnormativos?documento=2289. Acesso em: 20 dez. 2019.

BRASIL. Lei 13.104, de 9 de março de 2015. Brasília: Distrito Federal. Disponível em: http://www.planalto.gov.br/ ccivil_03/_ato2015-2018/2015/lei/L13104.htm\&gt. Acesso em: 30 dez. 2019.

CAMPOS, A. H.; CORRÊA, L. R. Direitos humanos das mulheres. Curitiba: Juruá, 2012.

CANOFRE, Fernanda. Juíza aposta em Justiça Restaurativa para trabalhar com famílias vítimas de violência doméstica. 2017. Disponível em: https://www.sul21.com.br/ultimas-noticias/geral/2017/10/juiza-aposta-em-justica-restaurativa-para-trabalhar-com-familias-vitimas-de-violencia-domestica/. Acesso em: 03 jan. 2020.

CEJUSC PONTA GROSSA. Resposta ao mensageiro enviado no dia 06 de junho de 2017. 2017. Ponta Grossa. Disponível em: https://www.tjpr.jus.br/documents/12054912/12392126/Justi\%C3\%A7a+Restaurativa+-+VD+-+PONTA+GROSSA.pdf/a05fb56c-4e99-4dd6-c308-82a0272ed124. Acesso em: 12 dez. 2019.

CERQUEIRA, D. et al (Orgs.). Atlas da violência 2019. Instituto de Pesquisa Econômica Aplicada; Fórum Brasileiro de Segurança Pública, Brasília: Rio de Janeiro: São Paulo, 2019.

COSTA, M. M. M; DIEHL, R. C. O redirecionamento da esfera pública pela coparticipação da sociedade civil aportes sobre a promoção do acesso à justiça nas comunidades da América do Sul. In: COSTA, M. M. M; DIEHL, R. C; PORTO, R. T. C. (Orgs). Direito na Atualidade. Curitiba: Multideia, 2017, p. 23-42.

COSTA, M. M. M.; PORTO, R. T. C. Justiça Restaurativa uma política humanizadora e não necessariamente de perdão: um olhar crítico e reflexivo na Resolução 225 do CNJ/2016. Revista Em Tempo, 16(01), 223-239, 2018.

DIAS, F. V.; COSTA, M. M. M. Sistema punitivo e gênero: uma abordagem alternativa a partir dos direitos humanos. Rio de Janeiro: Lumen Juris, 2013

FINCO, D.; VIANNA, C. C. Meninas e meninos. In: PINTO, Graziela Pinto (Coord). A mente do bebê: o fascinante processo de formação do cérebro e da personalidade. 2. ed. São Paulo: Duetto, 2008.

FROSSARD, Heloísa (Org.). Instrumentos Internacionais de direitos das mulheres. Brasília: Secretaria Especial de Políticas para as Mulheres, 2006.

GOMES, J. C. S.; GRAF, P. M. Circulando relacionamentos: uma nova abordagem para os conflitos decorrentes da violência de gênero. In: CRUZ, Fabrício Bittencourt da (Coord). Justiça restaurativa: horizontes a partir da Resolução CNJ 225. Brasília: CNJ, 2016. 
INSTITUTO MARIA DA PENHA (IMP). Enfrentar, por meio de mecanismos de conscientização e empoderamento, a violência doméstica e familiar contra a mulher. Essa é a nossa missão. 2018. Disponível em: http://www.institutomariadapenha.org.br/. Acesso em: 23 dez. 2019.

JACCOUD, Mylène. Princípios, tendências e procedimentos que cercam a Justiça Restaurativa. In.: SLAKMON, C.; DE VITTO, R.; PINTO, R. G. (Orgs.). Justiça Restaurativa. Brasília: Ministério da Justiça, 2005, 163-182.

MARTINS, A. P. A.; CERQUEIRA, D.; MATOS, M. V. M. A institucionalização das políticas públicas de enfrentamento à violência contra as mulheres no Brasil. Ipea: Brasília, 2015.

MINISTÉRIO DA MULHER, DA FAMÍLIA E DOS DIREITOS HUMANOS (MMFDH) Balanço anual: Ligue 180 recebe mais de 92 mil denúncias de violações contra mulheres. 2019a. Disponível em: https://www.mdh.gov.br/todas-as-noticias/2019/agosto/balanc. Acesso em: 23 dez. 2019.

MINISTÉRIO DA MULHER, DA FAMÍLIA E DOS DIREITOS humanos (MMFDH). Ligue 180 Central de Atendimento à Mulher: Relatório 2018. 2019b. Disponível em: https://www.mdh.gov.br/informacao-ao-cidadao/ouvidoria/relatorios-ligue-180. Acesso em: 09 jan. 2020.

MORAIS, J. L. B.; SPENGLER, F. M. Mediação e arbitragem: alternativas à jurisdição. 2. ed. Porto Alegre: Livraria do Advogado, 2008.

NORDENSTAHL, Ulf Christian Eiras. Contribuições da Vitimologia à Justiça Restaurativa. In: SPENGLER, F. M.; LUCAS, D. C. (Orgs.). Justiça Restaurativa e mediação: políticas públicas no tratamento dos conflitos sociais. Ijuí: Ed. Unijuí, 2011.

ORGANIZAÇÃO DAS NAÇÕES UNIDAS. Resolução 12. Princípios básicos para utilização de programas de justiça restaurativa em matéria criminal. 24 de julho de 2002. 2002. Disponível em: http://www.juridica.mppr.mp.br/ arquivos/File/MPRestaurativoEACulturadePaz/Material_de_Apoio/Resolucao_ONU_2002.pdf. Acesso em: 05 abr. 2019.

PRANIS, Kay. Processos circulares. São Paulo: Palas Athena, 2010.

PRUDENTE, Neemias Moretti. A Justiça Restaurativa e experiências brasileiras. In: SPENGLER, F. M.; LUCAS, D. C. (Orgs.). Justiça Restaurativa e mediação: políticas públicas no tratamento dos conflitos sociais. Ijuí: Ed. Unijuí, 2011.

SAFFIOTI, Heleieth. A mulher na sociedade de classes: mito e realidade. São Paulo: Expressão Popular, 2013.

SILVA, T. D.; OLIVEIRA, L. D. O funk e a apologia à violência sexual na era digital. Revista Meritum, Belo Horizonte, v. 14, n. 2, p. 172-187, jul./dez. 2019.

ZEHR, Howard. Trocando as lentes: um novo foco sobre o crime e a justiça. São Paulo: Palas Athena, 2008.

Recebido/Received: 07.06.2020.

Aprovado/Approved: 26.09.2020. 